\title{
Assessment of Tuber Yield Stability and Adaptability of Some Elite Yam Genotypes in the Guinea Savannah Ecology of Northern Ghana
}

\author{
Joseph Adjebeng-Danquah (D), Kwabena Acheremu, Emmanuel Boachie Chamba, \\ Freda Ansaah Agyapong, and Alhassan Sayibu
}

CSIR-Savanna Agricultural Research Institute, P. O. Box TL 52, Tamale, Ghana

Correspondence should be addressed to Joseph Adjebeng-Danquah; barchus2003@yahoo.com

Received 20 November 2020; Revised 3 February 2021; Accepted 1 March 2021; Published 22 March 2021

Academic Editor: Isabel Marques

Copyright (C) 2021 Joseph Adjebeng-Danquah et al. This is an open access article distributed under the Creative Commons Attribution License, which permits unrestricted use, distribution, and reproduction in any medium, provided the original work is properly cited.

\begin{abstract}
Studies were conducted to determine tuber yield stability and adaptability of some elite yam (Dioscorea sp.) genotypes in northern Ghana. Ten elite exotic yam genotypes alongside one locally cultivated farmer-preferred variety, Laribako, were grown in five environments between 2010 and 2012. These 11 genotypes were arranged in a randomised complete block design with three replications and assessed for tuber yield and yield components. Analysis of variance indicated significant $(p<0.05)$ genotypic variation for tuber yield and the yield components studied. Genotype $\times$ environment interaction effect was significant $(p<0.05)$ for tuber yield and mean tuber weight but not significant $(p>0.05)$ for number of tubers per mound. Apart from genotype 95/ 18922, all the exotic genotypes had significantly $(p<0.05)$ higher tuber yields than the local check, Laribako. The highest tuber yield $\left(16.03 \mathrm{t} \mathrm{ha}^{-1}\right)$ across environments was obtained from $96 / 19158$ followed by $95 / 00594\left(14.9 \mathrm{t} \mathrm{ha}^{-1}\right)$. According to the additive main effect multiplicative interaction (AMMI) analysis, genotype $(\mathrm{G})$, environment (E), and GxE interaction, respectively, explained $39.71 \%, 36.03 \%$, and $24.26 \%$ of the total sum of squares for tuber yield. For number of tubers per plant, GxE effect explained the greatest percentage $(60.46 \%)$ of the total sum of squares compared to genotype effect $(22.00 \%)$ and environment effect (17.54\%). The local variety, Laribako, was more stable across all environments though low yielding compared to the exotic genotypes. Three genotypes, 95/19158, 95/19177, and 96/02025, were more stable across environments than the other exotic genotypes. Genotype 95/18544 was the most sensitive and for that matter responded positively in the favorable environments. The study identified genotypes with specific and general adaptation potential across different environments for tuber yield that can be further tested in on-farm trials for possible release.
\end{abstract}

\section{Introduction}

Yam (Dioscorea sp.) is among the oldest recorded food crops believed to have originated in tropical areas [1]. Though six economically important species $(D$. rotundata, $D$. alata, $D$. caryensis, D. esculenta, D. dometorum, and D. bulbifera) are grown as staple foods in Africa [2], D. rotundata is the most widely cultivated within the yam zones of West Africa. Sub-Saharan Africa accounts for $70 \%$ of world yam production [3], and in Ghana, in particular, the crop is cultivated in 34 out of the 43 agriculturally important districts in the Guinea savannah zone in the north, savannah transition zones in the middle belt and forest zones as well as the costal savannah zones in the south [4]. About 76 percent of yam production takes place in the Brong Ahafo, Northern, and Eastern regions, which account for 39, 25, and 12 percent of total production, respectively, while the remaining 24 percent of production is distributed throughout the Upper West, Ashanti, Volta, and Western regions [5].

Ghana is the third largest producer of yam in Africa behind Nigeria and Cote d'Ivoire [6]. Yam is a vital crop not only for Ghana's domestic market but also to the international market as well. It serves as the main source of income and food security crop for most of the farmers in the 
Northern Region [7]. Ghana earned over US \$1.8 million in 2016 from the export of yam as a result of increased production of over seven million metric tonnes of yam. This made yam the number one foreign exchange earner for the country among all arable crop commodities [6].

Despite these important roles played by yam in ensuring food security and income generation, few improved varieties exist for cultivation by farmers. Most farmers in northern Ghana still prefer and cultivate their local varieties which though low yielding and susceptible to pests and diseases, still meet their food requirements [8]. Kusi et al. [9] observed that pests and diseases occurrences in yam cultivation are prevalent at earlier stages of growth and hence proposed both preplanting and postplanting protective treatments to ensure successful production of yam. However, several agronomic interventions on enhancing tuber yield have been made in yam research, and aspects of the genetic improvement of the crop are still at rudimentary stage with only few varieties released after introduction and evaluation of exotic genotypes in Ghana (the first official release was done in 2005) [10]. However, these have failed to adapt to all ecologies in Ghana. Most often, these introduced genotypes also fail to adapt to the local environments due to genotype $\times$ environment interaction which occurs as a result of differential responses of genotypes to different environmental conditions [4].

Earlier reports [11-13] have attributed variation in yield performance of yam to inherent genotypic characteristics, as well as preferences for different environmental conditions $[14,15]$. Therefore, careful evaluation is critical in identifying the suitable genotypes that will give the highest possible yield in different environments [16]. High yield and stability of genotypes across different environments are very important attributes desired by plant breeders. As a result, breeding materials are tested in diverse environments to assess the consistency in genotypic performance in order to identify superior ones for wider or specific adaptation [17, 18]. Genotypes whose $\mathrm{G} \times \mathrm{E}$ interaction effect remains insignificant from one environment to the other and across years are considered as stable $[14,19]$.

Though several methods have been used to assess genotype $\times$ environment interaction and stability for yield in crops, the additive main effect and multiplication interaction (AMMI) and genotype main effect and genotype $\times$ environment (GGE) biplot analyses which combine principal component analysis (PCA) and a graphical explanation of GEI have been very useful in recent times. The AMMI model integrates analysis of variance (ANOVA) and PCA for the analysis of stability of genotypes in multienvironment trials [20] and also estimates the contribution of each genotype and environment to the total GEI variation [21]. De Oliveira et al. [22] assessed the adaptability and stability of yellow passion fruit varieties in Brazil and suggested that the use of the AMMI stability value and yield stability in a single nonparametric index was useful for discriminating genotypes with superior and stable fruit yield. The GGE biplot on the other hand provides graphical representation of genotypes' adaptation to particular environments and facilitates the identification of representative environments, detects the ability of test environments to discriminate and identifies stable genotypes in MET [20, 23]. Otoo et al. [15] observed differential performances of 12 yam genotypes in different ecologies using the GGE biplot. Ali et al. [17] also identified specifically adapted upland cotton genotypes for yield and fiber traits; likewise, Jahanzaib et al. [24] also estimated genotype $\times$ environment interaction for seed yield in groundnut and adaptability to specific environments in Iran. These findings suggest that the GGE biplot is an appropriate tool for assessing yam genotypes for yield stability and adaptability to specific yam growing areas. The objective of this study was to assess different yam genotypes for tuber yield stability and identification of elite yam genotypes adapted to specific environments within the Guinea savannah ecology of northern Ghana.

\section{Materials and Methods}

The study involved ten elite exotic yam genotypes (Table 1) obtained from the International Institute of Tropical Agriculture and one elite local farmer-preferred variety, Laribako. The local variety used is widely cultivated in most of the yam growing communities in the Guinea savannah ecology. The trials were carried out at five locations in the Guinea savannah agroecological zone (each being a representative of a wider location) between 2010 and 2012. These locations were Mbowura, Lantinkpa, Yendi, and Nyankpala all in the Northern Region. The location (spatial) and year (temporal) combinations gave a total of five (5) environments (Table 2). The study areas have a monomodal rainfall pattern with an annual average of $1200 \mathrm{~mm}$. At each environment, the land was slashed and ploughed after which the plots were laid out in a randomised complete block design with three replications. Mounds were manually raised using a spacing of $1.2 \times 1.2 \mathrm{~m}$. Each genotype was assigned to a plot which consisted of 20 mounds. Staking was done at two months after planting using stakes measuring about $1.5 \mathrm{~m}$ high. Weeding was done as and when necessary. Harvesting was done at eight months after planting. At harvest, data were collected on tuber weight (kilograms) and number of tubers per mound. Tuber yield $\left(\mathrm{t} \mathrm{ha}^{-1}\right)$ was then calculated as weight of tubers from the net plots and extrapolated to one hectare. Mean tuber weight (g) was also estimated as the weight of tubers harvested per plot divided by the number of tubers.

2.1. Data Analysis. The data were subjected to combined analysis of variance using Genstat 12.1 [25]. Mean comparison among genotypic performances at different locations was done using the least significant difference test (LSD at $5 \%)$.

2.2. Stability Analysis. Additive Main effect and Multiplicative Interaction (AMMI) analysis of variance was further carried out for tuber weight of the 11 yam genotypes obtained per plot across environments using the Genstat software [25]. The AMMI model combines the analysis of variance and principal component analysis in a single 
TABLE 1: List of the genotypes used for the study.

\begin{tabular}{lccc}
\hline No. & Genotypes & Code & Source \\
\hline 1 & $95 / 01942$ & G1 & IITA \\
2 & $95 / 18544$ & G2 & IITA \\
3 & $95 / 18922$ & G3 & IITA \\
4 & $95 / 18949$ & G4 & IITA \\
5 & $95 / 19156$ & G5 & IITA \\
6 & $95 / 19158$ & G6 & IITA \\
7 & $95 / 19177$ & G7 & IITA \\
8 & $96 / 00594$ & G8 & IITA \\
9 & $96 / 02025$ & G9 & IITA \\
10 & $96 / 02610$ & G10 & IITA \\
11 & Laribako & G11 & Local \\
\hline
\end{tabular}

TABLE 2: List of environments used for the evaluations.

\begin{tabular}{lccc}
\hline Code & Environment & Location & Year \\
\hline E1 & Mbo2010 & Mbowura & 2010 \\
E2 & Lan2011 & Lantinkpa & 2011 \\
E3 & Lan2012 & Lantinkpa & 2012 \\
E4 & Yen2012 & Yendi & 2012 \\
E5 & Nyan2012 & Nyankpala & 2012 \\
\hline
\end{tabular}

analysis [26]. The principal component analysis decomposes the GEI component of the overall phenotype. AMMI stability value and yield stability index (YSI) were computed according to Adjebeng-Danquah et al. [27].

The AMMI model according to Zobel et al. [28] is presented as

$$
Y_{i j}=\mu+g_{i}+e_{j}+\sum_{k=1}^{n} \lambda_{k} \alpha_{i k} \gamma_{i k}+e_{i j}
$$

where $Y_{i j}$ is the response of $i^{\text {th }}$ genotype in the $j^{\text {th }}$ environment, $\mu$ is the grand mean, $g_{i}$ is the mean of the $i^{\text {th }}$ genotype minus the grand mean, $e_{j}$ is the mean of the $j^{\text {th }}$ environment minus the grand mean, $\lambda_{k}$ is the square root of the eigenvalue of the PCA axis $k, \alpha_{i k}$, and $\gamma_{j k}$ are the principal component scores for PCA axis $k$ of the $i^{\text {th }}$ genotype and the $j^{\text {th }}$ environment, respectively, and $e_{i j}$ is the residual. The environment and genotypic PCA scores are expressed as unit vector times the square root of $\lambda_{k}$, i.e., environment PCA score $=\lambda_{k}^{0.5} \gamma_{j k}, 0.5$, genotype PCA score $=\lambda_{k}^{0.5} \alpha_{i k}$.

AMMI stability value (ASV) was calculated for each genotype according to the relative contributions of the principal component axis scores (IPCA1 and IPCA2) to the interaction sum of squares.

The AMMI stability value (ASV) as described by Purchase et al. [29] was calculated as follows:

$$
\mathrm{ASV}=\sqrt{\left[\frac{\mathrm{IPCA} 1_{\text {Sum of squares }}}{\mathrm{IPCA} 2_{\text {Sum of squares }}}\left(\mathrm{IPCA} 1_{\text {Score }}\right)\right]^{2}+\left(\mathrm{IPCA} 2_{\text {Score }}\right)^{2}}
$$

where IPCA $1_{\text {Sum of squares }} / \mathrm{IPCA} 2_{\text {Sum of squares }}=$ the weight given to the IPCA1-value by dividing the IPCA1 sum of squares (from the AMMI analysis of variance table) by the IPCA2 sum of squares. The larger the IPCA score, either negative or positive, the more adapted a genotype is to a certain environment. Smaller ASV scores indicate a more stable genotype across environments [30].

The yield stability index was also calculated using the sum of the ranking based on yield and ranking based on the AMMI stability value:

$$
\mathrm{YSI}=\mathrm{RASV}+\mathrm{RY} \text {, }
$$

where RASV = the rank of the genotypes based on the AMMI stability value and RY= the rank of the genotypes based on yield across environments (RY).

YSI incorporates both mean yield and stability in a single criterion. Low values of both parameters show desirable genotypes with high mean yield and stability [31, 32].

Subsequently, the GGE biplot method as proposed by Yan [33] was used to visualise the genotype main effect and genotype $\times$ environment interaction patterns in the data in a biplot. The "which-won-where" pattern was used to visually identify the high performing and adapted as well as those suitable for the different test environments. This was carried out using the $R$ software package [34]. 


\section{Results}

Analysis of variance showed significant $(p<0.05)$ interaction and highly significant $(p<0.001)$ main effects for tuber yield (Table 3 ). Genotype effect explained $39.71 \%$ of the total sum of squares due to treatment followed by environment (36.03\%) and interaction effect (24.26\%). Only the first interaction principal component axis (IPCA 1) was significant and accounted for $59.74 \%$ of the interaction sum of squares with the IPCA2 accounting for $24.36 \%$.

3.1. Mean Performance of Genotypes in Five Environments. The performance of the 11 elite yam genotypes in each of the five environments is presented in Table 4. At Mbowura 2010, tuber yield ranged between $8.17 \mathrm{tha}^{-1}$ (Laribako) and $14.14 \mathrm{t} \mathrm{ha}^{-1}$ (95/ 19158) with a mean of $12.31 \mathrm{t} \mathrm{ha}^{-1}$. Tuber yield at Lantinkpa 2011 also varied from 10.88 to $18.33 \mathrm{tha}^{-1}$ for Laribako and 96/00594 respectively. Average tuber yield recorded at Lantinkpa 2012 was $13.45 \mathrm{tha}^{-1}$ and varied from 9.81 to $16.53 \mathrm{t} \mathrm{ha}^{-1}$ for Laribako and 96/00594, respectively. Genotype 95/19156 $\left(8.50 \mathrm{t} \mathrm{ha}^{-1}\right)$ had the lowest tuber yield at Yendi 2012, with 95/19158 (19.79t/ha) producing the highest yield. The lowest tuber yield at Nyankpala 2012 was $4.31 \mathrm{tha}^{-1}$ from 95/18922 which was lower than the farmer-preferred variety, Laribako. The highest tuber yield obtained in a particular environment $\left(19.79 \mathrm{tha}^{-1}\right)$ was from 95/ 19158 at Yendi 2012. Also, genotype 95/19158 had the highest overall mean tuber yield $\left(16.03 \mathrm{t} \mathrm{ha}^{-1}\right)$ across environments, which was significantly higher than eight of the other genotypes including the farmer-preferred variety, Laribako. Apart from genotypes 95/18544, 95/19156, and 95/18922, all the exotic genotypes had significantly higher tuber yield than the farmerpreferred variety. The lowest tuber yield recorded among the genotypes was $4.31 \mathrm{t} \mathrm{ha}^{-1}$ from 95/18922 at Nyankpala 2012. Lantinkpa 2011 was the environment with the highest average genotypic performance $\left(15.18 \mathrm{t} \mathrm{ha}^{-1}\right)$ with the Nyankpala 2012 giving the lowest average yield $\left(9.40 \mathrm{t} \mathrm{ha}^{-1}\right)$.

3.2. Ranking of Genotypes Based on Yield and Stability. Ranking of genotypes based on tuber yield, AMMI stability value (ASV), and yield stability index (YSI) is presented in Table 5. Genotype 95/18922 had the lowest ASV making it the most stable or nonresponsive. On the other hand, genotype 95/19158 with the highest ASV score was the most unstable or responsive genotype. In terms of yield, the reverse was the case. Genotype 95/19158 with the highest mean tuber yield across environments was ranked as number one. Based on the yield stability index (ranking of ASV + ranking of tuber yield), genotype 96/00594 was ranked as the best genotype combining high yield with high stability. The highest yielding genotype, $95 / 19158$, was ranked $5^{\text {th }}$ overall due to its low ranking according to the ASV. Two genotypes, 96/00594 and 96/02610, combined high yield with high stability, whereas $95 / 19158$ can be considered as high yielding and moderately stable. On the other hand, 95/19177 can be considered as high yielding and unstable whilst the lowest yielding genotypes with high stability can be considered unresponsive to the environment.
3.3. AMMI Selection of Best Performing Genotypes in Different Environments. Four top genotypes selected for Mbowura 2010 were in the order, 96/02610,95/19158, 95/01942, and 96/00594 (Table 6). At Lantinkpa 2011, the top four selected genotypes were 96/00594, 95/19158, 95/18544, and95/18949. Genotypes 96/00594, 95/19158, 96/02610, and 95/19156 were selected as the best performers at Lantinkpa 2012 whereas at Nyankpala 2012, genotypes 95/19158, 96/02025, 96/00594, and $95 / 19177$ were selected as the top four best performers. At Yendi 2012, genotypes 95/19158, 95/19177, 96/00594, and $96 / 02610$ were selected as the best performers. Both genotypes $95 / 19158$ and $96 / 00594$ were each selected as the top genotypes in two out of the five environments whilst 95/ 19158 was selected as the second best in three out of the five environments. Genotype 96/00594 was also selected as the third and fourth best in two out of five environments. Lantinkpa 2011 was the environment where genotypes had the highest average tuber yield with Nyankpala 2012 being the lowest yielding environment.

3.4. Discriminatory Ability and Representativeness of the Different Environments. Average-environment view of the 11 genotypes evaluated in five environments is presented in Figure 1. The environment vector with the smallest angle with the AEA is more representative of the other test environments. Therefore, E4, E2, and E3 were more representative than the other environments. E1 and E5 were the least representative, whereas E2 and E3 were identified as good for selecting generally adapted genotypes. The length of the environment vector indicates its discriminatory ability. Therefore, E5 was the most discriminating environment and as such more suitable for initial selection of genotypes for tuber yield.

3.5. Relationships between Test Environments. The environment vector view of the biplot for tuber yield of 11 genotypes in five environments indicates the correlation between the different environments (Figure 2). The angle between two environments indicates their correlation. Environments with acute angles are highly correlated whereas environments with obtuse angle represent negative correlation. In this case, E4 (Yendi 2012) and E5 (Nyankpala 2012) were highly and positively correlated, whereas environments E1 (Mbowura 2010), E2 (Lantinkpa 2011), and E3 (Lantinkpa 2012) were also highly positively correlated. There was a weak correlation between E1 and E5.

3.6. Mean Performance versus Stability. The GGE biplots in Figure 3 present mean vs. stability display of the 11 yam genotypes in five environments. The single environmental line that passes through the biplot origin and the average tester (vertical line) is referred to as average tester coordinate axis. The vertical line separates genotypes with below average means (to the opposite in direction of the arrow) from those with above-average means, with lines parallel to the vertical line indicating genotypic stability. Based on this information, 
TABle 3: AMMI analysis of variance for 11 elite yam genotypes evaluated in five environments for tuber yield.

\begin{tabular}{lcccc}
\hline & & \multicolumn{3}{c}{ Tuber yield } \\
Source of variation & Df & Sum of squares & Mean squares & \% of treatment SS \\
\hline Treatments & 54 & 1622.70 & $30.05^{* * *}$ & 39.71 \\
Genotypes (G) & 10 & 644.40 & $64.44^{* * *}$ & 36.03 \\
Environments (E) & 4 & 584.70 & $146.17^{* * *}$ & $22.85^{* * *}$ \\
Block & 10 & 228.50 & $9.84^{*}$ & 24.26 \\
GxE & 40 & 393.70 & $18.09^{* *}$ & $8.72 \mathrm{~ns}$ \\
IPCA1 & 13 & 235.20 & 3.92 & 5.53 \\
IPCA2 & 11 & 95.90 & 6.53 & 24.36 \\
Residuals & 16 & 652.70 & 15.27 & \\
Error & 100 & 2504.00 & 164 & \\
Total & 164 & &
\end{tabular}

TABLe 4: Mean tuber yield $\left(\mathrm{t} \mathrm{ha}^{-1}\right)$ of 11 elite yam genotypes evaluated in five environments.

\begin{tabular}{|c|c|c|c|c|c|c|c|}
\hline Genotypes & Code & Mbo2010 & Lan2011 & Lan2012 & Yen2012 & Nyk2012 & Mean \\
\hline $95 / 01942$ & G1 & 13.40 & 14.56 & 12.68 & 10.07 & 9.33 & 12.01 \\
\hline $95 / 18544$ & $\mathrm{G} 2$ & 12.41 & 16.87 & 12.13 & 8.59 & 5.60 & 11.12 \\
\hline $95 / 18922$ & G3 & 9.44 & 13.40 & 9.98 & 10.32 & 4.31 & 9.49 \\
\hline $95 / 18949$ & G4 & 12.59 & 16.41 & 14.44 & 9.79 & 10.65 & 12.78 \\
\hline $95 / 19156$ & G5 & 12.48 & 12.38 & 14.72 & 8.50 & 7.36 & 11.09 \\
\hline $95 / 19158$ & G6 & 14.14 & 17.59 & 15.92 & 19.79 & 12.69 & 16.03 \\
\hline $95 / 19177$ & G7 & 11.92 & 15.86 & 13.33 & 16.69 & 11.16 & 13.79 \\
\hline $96 / 00594$ & G8 & 12.85 & 18.33 & 16.53 & 15.60 & 11.32 & 14.93 \\
\hline $96 / 02025$ & G9 & 12.15 & 14.61 & 13.19 & 11.50 & 11.55 & 12.60 \\
\hline $96 / 02610$ & G10 & 15.81 & 16.04 & 15.23 & 13.63 & 10.00 & 14.14 \\
\hline Laribako & G11 & 8.17 & 10.88 & 9.81 & 10.91 & 9.49 & 9.85 \\
\hline Mean & & 12.31 & 15.18 & 13.45 & 12.31 & 9.40 & 12.53 \\
\hline LSD (0.05) & & 5.10 & 3.99 & 3.82 & 4.99 & 3.61 & 1.90 \\
\hline Variance & & 12.81 & 9.87 & 9.11 & 18.11 & 10.08 & 11.99 \\
\hline
\end{tabular}

Key: Mbo2010= Mbowura 2010 (E1), Lan2011 = Lantinkpa 2011 (E2), Lan2012 = Lantinkpa 2012 (E3), Yen2012 = Yendi 2012 (E4), Nyk2012= Nyankpala 2012 (E5).

TABle 5: Ranking of 11 yam genotypes based on tuber yield, AMMI stability value, and yield stability index in five environments.

\begin{tabular}{|c|c|c|c|c|c|c|c|c|}
\hline Genotype & Mean & IPCA [1] & IPCA [2] & ASV & RASV & Rank_yield & YSI & YSI rank \\
\hline 96/00594 & 14.93 & -0.35 & 0.41 & 1.14 & 3 & 2 & 5 & 1 \\
\hline $96 / 02610$ & 14.14 & 0.40 & 0.13 & 1.36 & 4 & 3 & 7 & 2 \\
\hline $96 / 02025$ & 12.60 & -0.05 & -0.93 & 0.13 & 2 & 6 & 8 & 3 \\
\hline $95 / 18949$ & 12.78 & 0.80 & -0.57 & 4.36 & 6 & 5 & 11 & 4 \\
\hline $95 / 19158$ & 16.03 & -1.46 & 0.49 & 13.41 & 11 & 1 & 12 & 5 \\
\hline $95 / 01942$ & 12.01 & 0.63 & -0.41 & 2.84 & 5 & 7 & 12 & 6 \\
\hline $95 / 18922$ & 9.49 & -0.02 & 1.12 & 0.05 & 1 & 11 & 12 & 7 \\
\hline $95 / 19177$ & 13.79 & -1.28 & 0.25 & 10.40 & 9 & 4 & 13 & 8 \\
\hline $95 / 19156$ & 11.09 & 1.05 & -0.58 & 7.18 & 8 & 9 & 17 & 9 \\
\hline Laribako & 9.85 & -1.00 & -1.01 & 6.51 & 7 & 10 & 17 & 10 \\
\hline $95 / 18544$ & 11.12 & 1.29 & 1.10 & 10.53 & 10 & 8 & 18 & 11 \\
\hline
\end{tabular}

TABLE 6: First four AMMI selections per environment.

\begin{tabular}{lccccccc}
\hline Number & Environment & Mean & Score & 1 & 2 & 3 \\
\hline 1 & Mbo2010 & 12.31 & 1.365 & $96 / 02610$ & $95 / 19158$ & $95 / 01942$ \\
2 & Lan2011 & 15.18 & 0.757 & $96 / 00594$ & $95 / 19158$ & $95 / 18544$ & $96 / 00594$ \\
3 & Lan2012 & 13.45 & 0.846 & $96 / 00594$ & $95 / 19158$ & $96 / 02610$ & $95 / 18949$ \\
4 & Nyk2012 & 9.40 & -0.679 & $95 / 19158$ & $96 / 02025$ & $96 / 00594$ \\
5 & Yen2012 & 12.31 & -2.289 & $95 / 19158$ & $95 / 19177$ & $96 / 00594$ & $95 / 19177$ \\
\hline
\end{tabular}




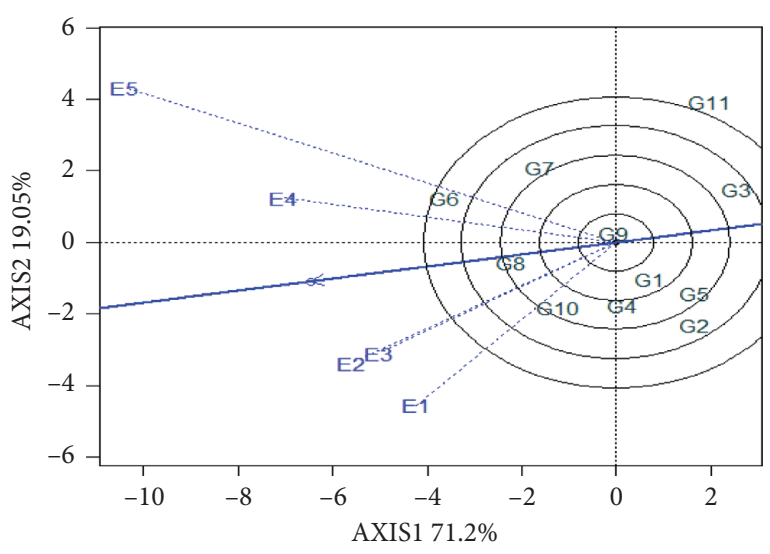

FIGURE 1: Discriminativeness vs. representativeness view of GGE biplot of genotypes across test environment. The biplot based on scaling $=0$; centering $=2 ; \quad S V P=2$; genotypes: $\mathrm{G} 1=95 / 0194$, $\mathrm{G} 2=95 / 18544, \quad \mathrm{G} 3=95 / 18922, \quad \mathrm{G} 4=95 / 18949, \quad \mathrm{G} 5=95 / 19156$, $\mathrm{G} 6=95 / 19158, \quad \mathrm{G} 7=95 / 19177, \quad \mathrm{G} 8=96 / 00594, \quad \mathrm{G} 9=96 / 02025$, $\mathrm{G} 10=96 / 02610$, and $\mathrm{G} 11=$ Laribako; and environments: $\mathrm{E} 1=$ Mbowura 2010, E2=Lantinkpa 2011, E3 = Lantinkpa 2012, E4 = Yendi 2012, and E5 = Nyankpala 2012.

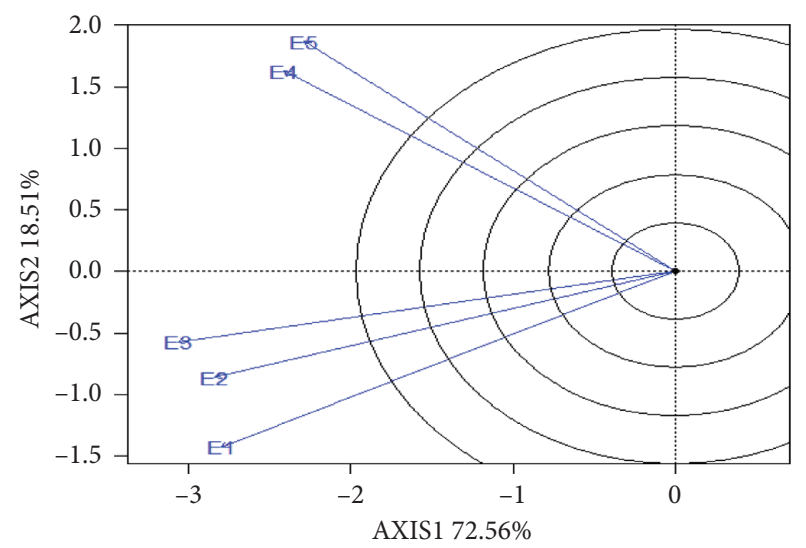

FIGURE 2: Relationship of test environment for tube yield across five environments. The biplot based on scaling by standard deviation; centering $=2$; $\mathrm{SVP}=2$; genotypes: $\mathrm{G} 1=95 / 0194, \mathrm{G} 2=95 / 18544$, G3 $=95 / 18922, \quad G 4=95 / 18949, \quad G 5=95 / 19156, \quad G 6=95 / 19158$, $\mathrm{G} 7=95 / 19177, \mathrm{G} 8=96 / 00594, \mathrm{G} 9=96 / 02025, \mathrm{G} 10=96 / 02610$, and G11 =Laribako; and environments: E1 = Mbowura 2010, E2 = Lantinkpa 2011, E3 = Lantinkpa 2012, E4= Yendi 2012, and E5 = Nyankpala 2012.

G6 (95/19/18) was the highest yielding genotype, with G3 (95/ 18949 ) being the lowest yielding. Genotypes G6, G8 (96/ 00594), G10 (96/02610), G7 (95/19177), and G4 (95/18949) had above-average performance. Genotype G8 with the shorter projection unto the average tester average coordinate axis was considered to have high yield and high stability across the environments. In contrast, (G6) 95/19158, though had the highest above-average yield, also had a long projection unto the ATC axis indicating low stability.

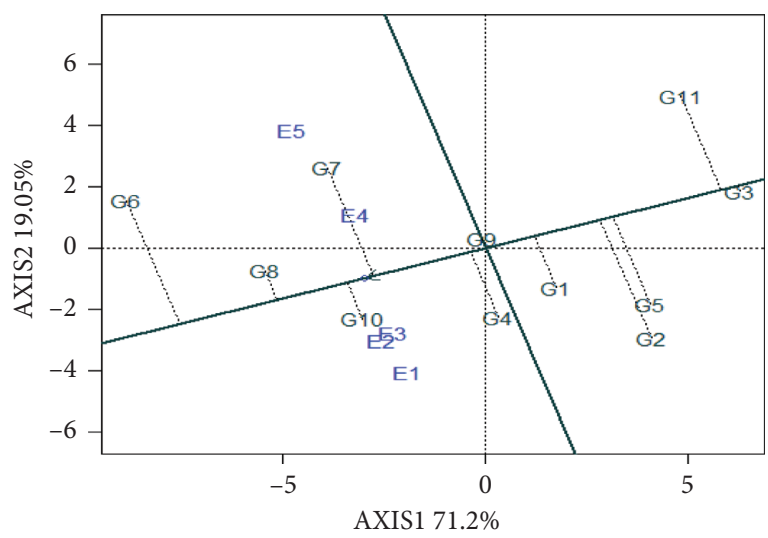

Figure 3: The average-environment coordination (AEC) view of GGE biplot to show the mean performance and stability of the genotypes. The biplots were based on scaling $=0$, centering $=2$, and SVP $=1$. Genotypes: $\mathrm{G} 1=95 / 0194, \mathrm{G} 2=95 / 18544, \mathrm{G} 3=95 / 18922$, $\mathrm{G} 4=95 / 18949, \quad \mathrm{G} 5=95 / 19156, \quad \mathrm{G} 6=95 / 19158, \mathrm{G} 7=95 / 19177$, $\mathrm{G} 8=96 / 00594, \quad \mathrm{G} 9=96 / 02025, \quad \mathrm{G} 10=96 / 02610, \quad$ and $\mathrm{G} 11=$ Laribako; environments: E1 = Mbowura 2010, E2 = Lantinkpa 2011, E3 = Lantinkpa 2012, E4= Yendi 2012, and E5 = Nyankpala 2012.

3.7. Adaptability of Genotypes to Specific Environments. The polygon view drawn on the farthest genotypes is presented in Figure 4. The vertex genotypes indicate the best or poorest in the environments within that sector. The biplot was divided into five sectors. Only sectors 1 and 5 had environments. Sector 1 had four environments; E2, E3, E4, and E5 whilst sector 5 had only one environment, E1. A genotype at the apex of a vertex represents the winning genotype in all the environments within that sector. In this case, 95/19158 (G6) was the winning genotype at Lantinkpa 2011 (E2), Lantinkpa 2012 (E3), Nyankpala 2012 (E4), and Yendi 2012 (E5). The proximity of a genotype to an environment indicates that the genotype or group of genotypes had their best performance or more adapted to that particular environment. This therefore means that genotype 96/2610 (G10) was better adapted to the prevailing conditions at Mbowura 2010, Lantinkpa 2011, and Lantinkpa 2012.

3.8. Comparison Biplot Showing Ideal Genotype for High and Stable Yield. From Figure 5, G8 (9/00594) was closer to the centre of the concentric circles (ideal genotype) and therefore more desirable since it combines high tuber yield with high stability across environments. Though G6 (95/ 19158) had the highest average tuber yield across locations, it was considered less desirable compared to G8 (9/00594). Genotypes on the right side of the biplot had below average performance. G11 (Laribako) and G3 (95/18922) were the poorest in terms of tuber yield and stability due to their consistently poor performance across environments as indicated by their distance from the centre of the concentric circles. 


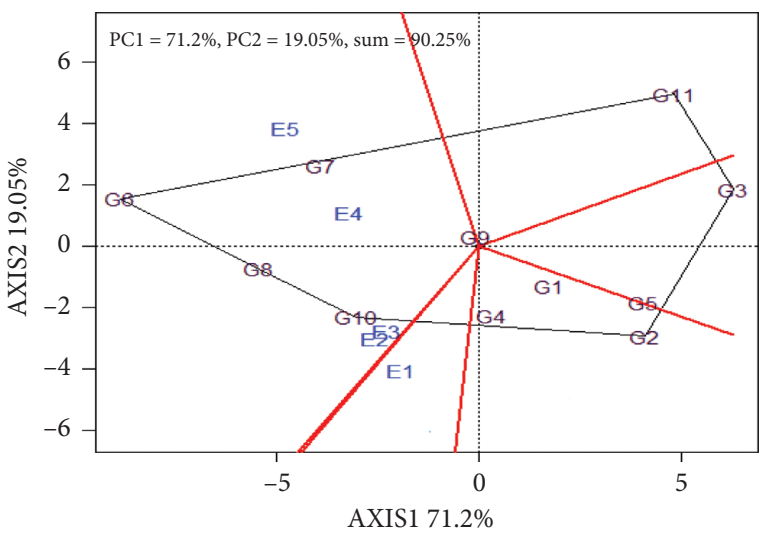

FIGURE 4: The polygon view of GGE biplot based on genotype scaling showing which genotype won in which locations for tuber yield. The biplots were based on scaling $=0$, centering $=2$, and $\mathrm{SVP}=1$. Genotypes: $\mathrm{G} 1=95 / 0194, \mathrm{G} 2=95 / 18544, \mathrm{G} 3=95 / 18922$, $\mathrm{G} 4=95 / 18949, \quad \mathrm{G} 5=95 / 19156, \quad \mathrm{G} 6=95 / 19158, \quad \mathrm{G} 7=95 / 19177$, $\mathrm{G} 8=96 / 00594, \quad \mathrm{G} 9=96 / 02025, \quad \mathrm{G} 10=96 / 02610, \quad$ and $\mathrm{G} 11=$ Laribako; environments: E1=Mbowura 2010, E2 = Lantinkpa 2011, E3 = Lantinkpa 2012, E4 = Yendi 2012, and E5 = Nyankpala 2012.

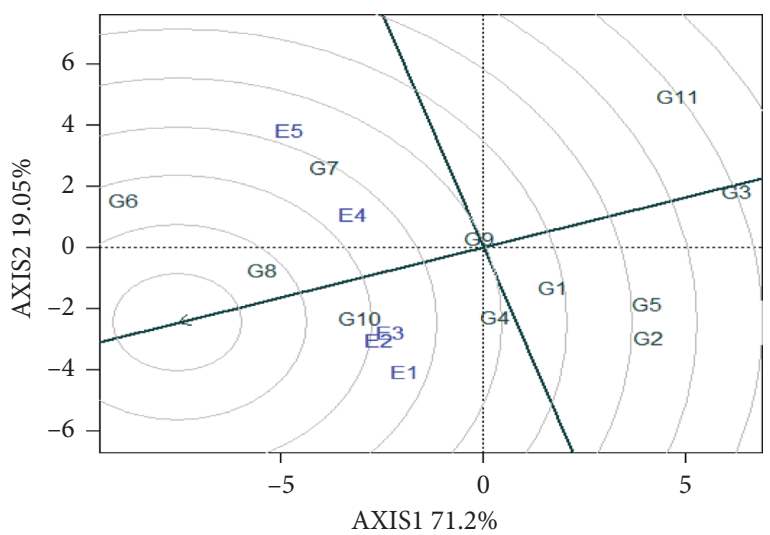

FIgURE 5: The average-environment coordination (AEC) view to rank genotypes relative to an ideal genotype. The biplot based on scaling $=0 ; \quad$ centering $=2 ; \quad S V P=1 ;$ genotypes: $\quad G 1=95 / 0194$, $\mathrm{G} 2=95 / 18544, \quad \mathrm{G} 3=95 / 18922, \quad \mathrm{G} 4=95 / 18949, \quad \mathrm{G} 5=95 / 19156$, G6 $=95 / 19158, \quad G 7=95 / 19177, \quad G 8=96 / 00594, \quad G 9=96 / 02025$, $\mathrm{G} 10=96 / 02610$, and $\mathrm{G} 11=$ Laribako; and environments: $\mathrm{E} 1=$ Mbowura 2010, E2=Lantinkpa 2011, E3=Lantinkpa 2012, E4 = Yendi 2012, and E5 = Nyankpala 2012.

\section{Discussion}

Tuber yield in yam like most quantitative traits is highly influenced by genotype $\times$ environment interaction $[4,23,35,36]$. This phenomenon confounds selection of such genotypes for general adaptation. In the present study, genotype, environment, and genotype $\times$ environment interaction effects significantly affected tuber yield in the genotypes studied. Nduwumuremyi et al. [37] indicated that the presence of significant genotype $\times$ environment interaction effect for quantitative traits such as tuber yield can seriously limit the efforts made in selecting superior genotypes for different environments. This is because such performance cannot be replicated in environments with different growing conditions. Different genotypes of yam possess inherent varietal characteristics and preferences for different environmental conditions [13-15] especially for foreign genotypes that have been introduced into new environments. Therefore, genotypes need to be evaluated across different environments in order to identify specific locations that best suit them and where such genotypes can attain their full yield potential [19]. The use of stability analysis enables breeders to quantify the extent of genotype $\times$ environment interaction and characterise genotypes as widely adapted (to several environments) or specifically adapted (to single or few environment) based on stability indices [38].

A genotype is considered to be stable if it has a low degree of fluctuation in its yielding ability when planted over diverse environments [39, 40]. Osei et al. [35] and Yan and Tinker [23] also suggested that genotypes whose variances remain relatively constant from one environment to the other are considered stable. However, a consistently poor genotype can still be stable. Therefore, stability should always be considered in addition to superior performance for that trait of interest. Purchase et al. [29] therefore proposed a yield stability index that combines ranking based on high yield and stability (based on the AMMI stability value) into a single index, the yield stability index (YSI). The AMMI analysis identifies specific genotypes which are stable across environments [20, 21]. From this study, genotype 95/19158 ranked highest in terms of yield across environments, but low in terms of stability. This implies that it responded positively under favorable environmental conditions but poorly under the less favorable environmental, thus suggesting specific adaptation. With good agricultural practices, such a genotype would be ideal genotype for high input agriculture of growth in favorable environmental conditions (agronomic stability).

Though the yield of locally adaptable genotypes tends to remain consistent across environments, they still fail to respond positively even in favorable environments. Such genotypes are classified as unresponsive to the environmental conditions (biologically stable) and remain the best insurance for farmers in harsh conditions. Other genotypes however tend to respond positively to favorable environments whilst their yields remain moderate under harsh conditions. Such genotypes are normally selected for specific environments where they could exhibit their full yield potential. In the present study, the yield of the farmer variety, Laribako, remained consistent, though low across the five environments. However, the tuber yield of genotype 95/ 19158 remained moderatively consistent across environments and was the highest ranked genotype in four out of the five environments.

The genotype main effect and genotype $\times$ environment (GGE) biplot visualizes the main effect of genotype as well as genotype $\times$ environment interaction [41]. The "which-wonwhere" pattern of the polygon view-based interaction of GGE biplot is useful for the identification of elite genotypes 
in single or multiple environments [42]. Genotypes at the apices of the polygon (vertex cultivars) represent the best performing genotypes of all environments within that sector. In the present study, the use of the GGE biplots revealed the genotypes that combined high mean performance with high stability as well as preferences and adaptation to some specific environments (Figures 3 and 4). This indicated that genotype 95/19177 was adapted to the environments, E4 (Yendi 2012) and E5 (Nyankpala 2012) whereas genotypes 95/18544 and 96/00594 had their best performances at E1 (Mbowura 2010), E2 (Lantinkpa 2011), and E3 (Lantinkpa 2012). However, genotype 95/19158 was adapted to four environments; E1 (Mbowura 2010), E2 (Lantinkpa 2011), E3 (Lantinkpa 2012), and E4 (Yendi 2012). This phenomenon of specific adaptation or environmental preferences by different yam genotypes has also been reported in earlier studies on genotype $\times$ environment analysis. Otoo and Asiedu [43] evaluated and identified specifically adapted Dioscorea rotundata "Tela" genotypes in Ghana. Otoo et al. [15] also in a study involving 12 Dioscorea rotundata genotypes identified specifically adapted cultivars in 16 environments using the GGE biplot, again confirming the environmental specificity of different yam genotypes.

According to Yan and Tinker [23], an ideal genotype is one that combines high mean yield with high level of stability. Though such an ideal genotype may not exist under natural conditions, it is used as a reference for genotype evaluation [44]. The centre of the concentric circles (Figure 5) represents the position of an ideal genotype, which is defined by a projection onto the mean-environment axis that equals the longest vector of the genotypes that had aboveaverage mean yield and by a zero projection onto the perpendicular line (zero variability across environments). A genotype is more desirable if it is closer to the ideal genotype. It allows the evaluation of genotypes according to their nearness or how far they are to this centre [44, 45]. From Figure 5, G8 (9/00594) was the most desirable genotype which combined high yield with high stability across environments. Though G6 (95/19158) had the highest average tuber yield across locations, it was considered less desirable compared to G8 (9/00594). Genotypes on the right side of the biplot had below average performance. Laribako (G11) and 95/18922 (G3) were undesirable due to their consistently poor performances across environments as indicated by their distance from the centre of the concentric circles [46]. This study provides novel information on genotype $\times$ environment interaction effect on yam yield in the Guinea savannah ecology of Ghana and portrays the need to test yam genotypes for environmental specificity before their release for cultivation by farmers in the area.

\section{Conclusion}

Adaptation and stability of yield performance are very important in developing new yam varieties especially for introduced genotypes. The different genotypes showed adaptation to different environments. Genotype 95/19158 had the highest overall performance across environments with moderate stability. Genotypes 96/00594 and 96/02610 combined high yield with high stability according to the yield stability index (YSI). Genotype 95/19177 though relatively high yielding was less stable according to the AMMI stability value and yield stability index and therefore suited for specific adaptation. The farmer-preferred variety, Laribako, was consistently low yielding across environments. From the study, genotype 95/19158 had specific adaptation whilst 96/00594,96/02610,96/02025, and 95/18949 had general adaptation. The findings from this study provide important information on the need for multilocational testing of new yam genotypes prior to release.

\section{Data Availability}

The data obtained in the experiment have been used in the writing of this manuscript.

\section{Conflicts of Interest}

The authors declare that they have no conflicts of interest regarding the publication of this paper.

\section{Acknowledgments}

The authors acknowledge the support of the Management and staff of the CSIR-Savanna Agricultural Research Institute, Nyankpala. Dr Stephen Asante, a former Deputy Director (2010 to 2014) of CSIR-SARI is duly acknowledged for his contributions during the conduct of this study through the West Africa Agricultural Productivity Programme project on "On-Farm evaluation of elite exotic and local yam genotypes for adaptation to the Guinea savannah ecology of Ghana”.

\section{References}

[1] H. D. Mignouna, M. M. Abang, R. Asiedu, and R. Geeta, “True yams (Dioscorea): a biological and evolutionary link between eudicots and grasses," Cold Spring Harbor Protocol, vol. 4, no. 11, pp. 1-7, 2009.

[2] J. W. Purseglove, Tropical Crops Monocotyledons, Elsevier, Amsterdam, Netherlands, 1972.

[3] N. A. Etim, D. Thompson, and C. E. Onyenweaku, "Measuring efficiency of yam (Dioscorea spp) production among resource poor farmers in rural Nigeria," Journal of Agriculture and Food Sciences, vol. 1, no. 3, pp. 42-47, 2013.

[4] E. Otoo, C. R. Okonkwo, and R. Asiedu, "Stability studies of hybrid yam genotypes in Ghana," Journal of Food, Agriculture and Environment, vol. 4, no. 1, pp. 234-238, 2006.

[5] P. Anaadumba, "Analysis of incentives and disincentives for yam in Ghana," Technical Notes Series, MAFAP, FAO, Rome, Italy, 2013, http://www.fao.org/3/a-at552e.pdf.

[6] FAO, Food and Agriculture Organization of the United Nations Rome, Rome, Italy, 2020, http://www.fao.org/faostat/en/ \#data/QV.

[7] MiDA, Commercial Seed Yam Production, Millennium Development Authority (MIDA), Accra, Ghana, 2008.

[8] S. K. Asante, G. W. K. Mensah, and E. Wahaga, "Farmers' knowledge and perception of insect pests of yam (Dioscorea pp.) and their indigenous control practices in the northern Ghana," Ghana Journal of Agricultural Science, vol. 40, no. 2, pp. 185-192, 2007. 
[9] F. Kusi, S. K. Asante, J. Adjebeng-Danquah et al., "Participatory integrated pest management strategy for improving shelf-life of yam (Dioscorea spp)," International Journal of Advance Agricultural Research, vol. 1, pp. 124-132, 2013.

[10] J. Sam and H. Dapaah, "West Africa agricultural productivity programme (WAAPP) Ghana," Baseline Survey Report, vol. 2, 2009.

[11] I. C. Onwueme and W. B. Charles, Tropical Root and Tuber Crops: Production Perspective and Future Prospects, pp. 40-51, FAO, Rome, Italy, 1994.

[12] C. L. A. Asadu, F. O. R. Akamigbo, F. I. Nweke, and H. C. Ezumah, "Evaluation of six cultivars of white yam (Dioscorea rotundata) across three yam-growing areas in southeastern Nigeria," The Journal of Agricultural Science, vol. 127, no. 4, pp. 463-468, 1996.

[13] R. Kapinga, N. Nangera, R. Asiedu, B. Chirimi, and S. Kaare, "Yams in the Tanzanian food and farming systems: implications for research and development," in Proceedings of the 7th Triennial Symposium of the International Society for Tropical Root Crops Africa Branch. (ISTRC-AB), Cotonou, Benin Republic, October 1998.

[14] G. Ssemakula and A. Dixon, "Genotype $\times$ environment interaction, stability and agronomic performance of carotenoidrich cassava clones," Scientific Research and Essay, vol. 2, pp. 390-399, 2007.

[15] E. Otoo, K. Osei, J. Adomako et al., "GGE biplot analysis of 12 Dioscorea rotundata genotypes in Ghana," Journal of Agricultural Science, vol. 10, no. 1, pp. 249-263, 2018.

[16] B. O. Ugwu, T. O. Ezulike, G. C. Orkwor, and E. C. Nwauzor, "Comparative analysis of costs and returns in dry and wet season planted yams in Benue State Nigeria," in Proceedings of the 7th Triennial Symposium of the International Society for Tropical Root Crops Africa Branch. (ISTRC-AB), pp. 167-173, Cotonou, Benin Republic, October 1998.

[17] I. Ali, N. U. Khan, M. Rahman et al., "Genotype by environment and biplot analyses for yield and fiber traits in upland cotton," International Journal of Agriculture and Biology, vol. 20, pp. 1979-1990, 2018.

[18] E. Otoo and R. Asiedu, "The performance profile of Dioscorea rotundata cultivar Dorban genotypes in Ghana using GGE biplot analysis," Journal of Food, Agriculture and Environment, vol. 7, no. 1, pp. 150-155, 2009.

[19] A. G. O. Dixon and E. N. Nukenine, "Genotype x environment interaction and optimum resource allocation for yield and yield components of cassava," African Crop Science Journal, vol. 8, pp. 1-10, 2000.

[20] M. Jamshidmoghaddam and S. S. Pourdad, "Genotype $\times$ environment interactions for seed yield in rainfed winter safflower (Carthamus tinctorius L.) multi-environment trials in Iran," Euphytica, vol. 190, no. 3, pp. 357-369, 2013.

[21] K. Hongyu, M. García-Peña, L. B. d. Araújo, and C. T. d. Santos Dias, "Statistical analysis of yield trials by AMMI analysis of genotype $\times$ environment interaction," Biometrical Letters, vol. 51, no. 2, pp. 89-102, 2014.

[22] E. J. De Oliveira, J. P. X. De Freitas, and O. N. De Jesus, "AMMI analysis of the adaptability and yield stability of yellow passion fruit varieties," Scientia Agricola, vol. 71, no. 2, pp. 139-145, 2014.

[23] W. Yan and N. A. Tinker, "Biplot analysis of multi-environment trial data: principles and applications," Canadian Journal of Plant Science, vol. 86, no. 3, pp. 623-645, 2006.

[24] M. Jahanzaib, N. Nawaz, H. Khurshid, S. A. Jan, M. Arshad, and I. Hassan, "Estimating genotype $\times$ environment interaction for groundnut seed yield across different ecological zones," International Journal of Agriculture and Biology, vol. 22, pp. 139-145, 2019.

[25] R. W. Payne, D. A. Murray, S. A. Harding, D. B. Baird, and D. M. Soutar, Genstat for Windows: Introduction, VSN International, Hemel Hempstead, UK, 12 edition, 2009.

[26] A. Agyeman, E. Parkes, and B. B. Peprah, "AMMI and GGE biplot analysis of root yield performance of cassava genotypes in the forest and coastal ecologies," International Journal of Agricultural Policy and Research, vol. 3, pp. 222-232, 2015.

[27] J. Adjebeng-Danquah, J. Manu-Aduening, V. E. Gracen, I. K. Asante, and S. K. Offei, "AMMI stability analysis and estimation of genetic parameters for growth and yield components in cassava in the forest and Guinea savannah ecologies of Ghana," International Journal of Agronomy, vol. 2017, Article ID 8075846, 10 pages, 2017.

[28] R. W. Zobel, M. J. Wright, and H. G. Gauch, "Statistical analysis of a yield trial," Agronomy Journal, vol. 80, no. 3, pp. 388-393, 1988.

[29] J. L. Purchase, H. Hatting, and C. S. van Deventer, "Genotype $\times$ environment interaction of winter wheat (Triticum aestivum L.) in South Africa: II. Stability analysis of yield performance," South African Journal of Plant and Soil, vol. 17, no. 3, pp. 101-107, 2000.

[30] E. Farshadfar, N. Mahmodi, and A. Yaghotipoor, "AMMI stability value and simultaneous estimation of yield and yield stability in bread wheat (Triticum aestivum L.)," Australian Journal of Crop Science, vol. 5, no. 13, pp. 1837-1844, 2011.

[31] R. Tumuhimbise, R. Melis, P. Shanahan, and R. Kawuki, "Genotype $\times$ environment interaction effects on early fresh storage root yield and related traits in cassava," The Crop Journal, vol. 2, no. 5, pp. 329-337, 2014.

[32] L. K. Bose, N. N. Jambhulkar, K. Pande, and O. N. Singh, "Use of AMMI and other stability statistics in the simultaneous selection of rice genotypes for yield and stability under directseeded conditions," Chilean Journal of Agricultural Research, vol. 74, no. 1, pp. 1-9, 2014.

[33] W. Yan, "GGEbiplot-a Windows application for graphical analysis of multi-environment trial data and other types of two-way data," Agronomy Journal, vol. 93, pp. 1111-1118, 2002.

[34] R. R Core Team, A Language and Environment for Statistical Computing, Statistical Computing, Vienna, Austria, 2018.

[35] M. K. Osei, B. Annor, J. Adjebeng-Danquah et al., "Genotype $\times$ environment interaction: a prerequisite for tomato variety development," in Recent Advances in Tomato Breeding and Production, S. T. Nyaku and A. Danquah, Eds., pp. 93113, Intechopen Limited, London, UK, 2018.

[36] C. N. Egesi, S. Ogunyomi, and R. Asiedu, "Genotype $\times$ environment interaction in water yam (Dioscorea alata) yield trials in five yam growing sites in Nigeria," Journal of Genetics and Breeding, vol. 59, pp. 81-88, 2005.

[37] A. Nduwumuremyi, R. Melis, P. Shanahan, and A. Theodore, "Interaction of genotype and environment effects on important traits of cassava (Manihot esculenta Crantz)," The Crop Journal, vol. 5, no. 5, pp. 373-386, 2017.

[38] E. J. Oliveira and I. J. Godoy, "Pod yield stability analysis of runner peanut lines using AMMI," Crop Breeding and Applied Biotechnology, vol. 6, pp. 311-317, 2006.

[39] S. K. Dhillon, G. Singh, B. S. Gill, and P. Singh, "Stability analysis for grain yield and its components in soybean [Glycine max (L.) Merril]," Crop Improvement, vol. 36, pp. 55-58, 2009.

[40] F. Gurmu, H. Mohammed, and G. Alemam, "Genotype $\times$ environment interactions and stability of soybean for 
grain yield and nutrition quality," African Crop Science Journal, vol. 17, no. 2, pp. 87-99, 2009.

[41] W. Yan, L. A. Hunt, Q. Sheng, and Z. Szlavnics, "Cultivar evaluation and mega-environment investigation based on the GGE biplot," Crop Science, vol. 40, no. 3, pp. 597-605, 2000.

[42] W. Yan and L. A. Hunt, "Interpretation of genotype $\times$ environment interaction for winter wheat yield in Ontario," Crop Science, vol. 41, no. 1, pp. 19-25, 2001.

[43] E. Otoo and R. Asiedu, "GGE biplot analysis of Dioscorea rotundata cultivar "Tela" genotypes in Ghana," Journal of Food, Agriculture and Environment, vol. 7, no. 1, pp. 134-139, 2009.

[44] E. Farshadfar, M. Mahnaz Rashidi, M. M. Jowkar, and H. Zali, "GGE Biplot analysis of genotype $\times$ environment interaction in chickpea genotypes," European Journal of Experimental Biology, vol. 3, no. 1, pp. 417-423, 2013.

[45] E. Kendal, S. Tekdal, and M. S. Sayar, "Assessment of the impact of ecological factors on yield and quality parameters in triticale using GGE biplot and AMMI analysis," Pakistan Journal of Botany, vol. 48, no. 5, pp. 1903-1913, 2016.

[46] E. Kendal, "Comparing durum wheat cultivars by genotype $\times$ yield $\times$ trait and genotype $\times$ trait biplot method," Chilean Journal of Agricultural Research, vol. 79, no. 4, pp. 512-522, 2019. 